\title{
Biomimetic Apatite Deposition in Modified Dulbecco's Phosphate-Buffered Saline Solution on the Alkali-Heat Treated TI6AL4V
}

\author{
${ }^{1}$ Nurul Hazwani Hanib, ${ }^{1}$ Fazlena Hamzah, ${ }^{2}$ Zarina Omar and ${ }^{1}$ Istikamah Subuki \\ ${ }^{1}$ Biocatalysis and Biobased Materials Technology Research Group, \\ Green Technology and Sustainable Development Research Community, \\ Faculty of Chemical Engineering, Universiti Teknologi MARA, \\ 40450 Shah Alam, Selangor, Malaysia \\ ${ }^{2}$ Faculty of Chemical Engineering, Universiti Teknologi MARA, 23200 Bukit Besi, \\ Dungun, Terengganu, Malaysia
}

\begin{abstract}
Simulated Body Fluid (SBF) solution has been used in biomimetic apatite coating. In some cases, the apatite formation on the metallic surface may take up to 4 weeks in SBF solution. Increasing the concentration of SBF seems to work in shortening the period of apatite formation yet the high concentration of unstable SBF solution is not easy to handle. Another potential solution that mimics human blood plasma to hasten the apatite formation is Dulbecco's Phosphate Buffered Saline. The aim of this research was to investigate the formation of apatite in Dulbecco's Phosphate Buffered Saline (DPBS) solution modified with $\mathrm{CaCl}_{2}$ and $\mathrm{MgCl}_{2}$ on the surface of alkali treated Ti6A14V. The bioactive surface on Ti6A14V was prepared by alkali etching using $5 \mathrm{M}$ $\mathrm{NaOH}$ and $5 \mathrm{M} \mathrm{KOH}$ and consolidated by heat treatment at 500 and $600^{\circ} \mathrm{C}$. The morphology structure, phase changes, wettability and chemical composition of apatite coating were characterised. The results demonstrated that apatite coating in globular rosette-like shape was formed on the surface treated with $\mathrm{NaOH}$ and subsequently heat-treated at $500^{\circ} \mathrm{C}$ within 3 days of immersion time in DPBS solution. Significantly, the DPBS solution can be used as a substitute in biomimetic solution for apatite coating at low processing temperatures for bioactive coating of the medical implant.
\end{abstract}

Key words: Ti6A14V, alkali treatment, heat treatment, biomimetic, Dulbecco's Phosphate Buffered Saline (DPBS), medical implant

\section{INTRODUCTION}

The bioactive surface has a special attention in orthopaedics and dental implants. The main advantage of the bioactive surface is its ability in promoting a good interfacial bonding between bone tissue and implants that are greater or equal to the host bone. There are various kinds of bioactive materials such as synthetic hydroxyapatite, bioglass and groups of Calcium Phosphate $(\mathrm{CaP})$. However, the bioactive ceramic material alone could not withstand the load-bearing situations since it has a low mechanical strength as compared to human bones. Thus, a metallic implant such as $\mathrm{Co}-\mathrm{Cr}$ alloys, stainless steel $316 \mathrm{~L}$ and Titanium (Ti) and its alloy are a wise choice for the load-bearing application. In medical implant surgery, Ti and its alloy were used widely due to its good mechanical strength owing to their light weight quality, excellent biocompatibility and high corrosion resistance. Ti and its alloy are also classified as a biotolerant material which formation of connective tissue does not adhere to the implant surface driving to implant rejection (Geetha et al., 2009). Mismatch of elastic moduli of $\mathrm{Ti}$ and host bone may lead to inappropriate stress distribution at the bone-implant interface which induces stress-shielding effects consequentially leading to bone degeneration and loosening of the implant (Engh Jr. et al., 2003). Rejection of implants could be avoided through various method of surface modification.

Coating metallic implants with bioactive materials such as Hydroxyapatite (HA) is an ideal approach in medical implant. Ti contribute to a good mechanical strength while HA enhances osseointegration and cellular interlocking which make the implant more suitable for load bearing application. Calcium phosphate-based coating that accelerates bone healing and bone apposition around the implant encourage to rapid biological fixation

Corresponding Author: Fazlena Hamzah, Biocatalysis and Biobased Materials Technology Research Group, Green Technology and Sustainable Development Research Community, Faculty of Chemical Engineering, Universiti Teknologi MARA, 40450 Shah Alam, Selangor, Malaysia 
(Cosma et al., 2015). A classic method of Calcium Phosphate (CaP) coating on metallic implant has been developed including anodizing, electrochemical deposition (Ducheyne et al., 1990; Ban and Maruno, 1993), sol-gel precipitate (Kaneko et al., 2009; Montenero et al., 2000) and plasma spray coating (De Groot et al., 1987; Klein et al., 1991). However, high processing temperature method of plasma spray will render to decomposition of hydroxyapatite (Jaworski et al., 2009). As reported by Huang et al. (2015), plasma spray coating produced a non-uniformly $\mathrm{HA}$ coating on the internal surface of porous Ti. With this limitation, an intense progress in surface implant modification has brought to the biomimetic methods, a promising technique for bioactive coating at low processing temperature.

A biomimetic solution of Simulated Body Fluid (SBF) was introduced by Kokubo et al. (1996). The ionic composition of SBF solution mimics human blood plasma with a $\mathrm{pH}$ of $7.2 \sim 7.4$ at $37^{\circ} \mathrm{C}$. The mechanism of bone-like apatite formation in biomimetic solution induced a uniformed coating on the porous and complex metal surface in room temperature conditions. Besides, the apatite deposition which acts as a bioactive interface layer between implant and cell can stimulate the growth of juxtaposed bone and the healing process. With this advantage, a various type of substrate has been tested including bio-glass and polymer-based implants in preparing bioactive composite implants for bone-like apatite forming.

$\mathrm{CaP}$ coatings on the metallic implant act as a barrier between the implant and bone tissue which provide a surface for bone easily growth, enhance mechanical interlocking and chemically bond at the bone-implant interface (Pasinli et al., 2010). CaP apatite coating via. SBF solution is a challenging process as the process could be considered as complex where high ion concentration in $\mathrm{SBF}$ is difficult to control due to the instability of the solution. SBF coating is an intricate process as many parameters need to be taken into account such as the pre-treatment steps (i.e., chemical, thermal) and control of $\mathrm{SBF}$ concentration in order to produce a calcium phosphate coating layer at the fastest rate. Moreover, the nucleation rate of apatite formation in a biomimetic solution of SBF takes more than $24 \mathrm{~h}$. Therefore, another potential biomimetic solution has been explored by researchers in $\mathrm{CaP}$ coating. One of the promising solutions is Phosphate Buffered-Saline (PBS) which has a similar composition with human blood plasma and SBF. Forsgren et al. (2007) used Dulbecco's $1 \times \mathrm{PBS}$ as a medium to deposit HA on the commercially pure Titanium (CpTi) surface. The result indicated that HA was deposited on CpTi after exposure to PBS within seven days of soaking. According to Chen et al. (2010), DPBS has great potential as a bone-like apatite self-induction on HA coated CpTi disc in $15 \mathrm{~min}$ of exposure time without the additional fibronectin. Meanwhile, the feasibility of biomimetic HA coating on Cobalt-Chromium (CoCr) substrates using PBS was studied by Lindahl et al. (2015). A homogenous coating composed of small flower-like crystal aggregates on the porous $\mathrm{CoCr}$ surface was formed which show the ability of PBS in nucleation of apatite after 3 day's soaking time. The HA layer was examined as nanocrystalline and amorphous HA.

Thus, in the present study, Dulbecco's Phosphate-Buffered Saline (DPBS) was used as a substitute for SBF solution in order to observe apatite deposition on the treated $\mathrm{Ti}$ surface. In order to initiate a bioactive surface, a simple combination step of alkali and thermal treatment were imposed on the metal substrate. Furthermore, the effect of potassium hydroxide $(\mathrm{KOH})$ on the topography of metal substrate was not widely discussed by the researcher as much as sodium hydroxide $(\mathrm{NaOH})$. Kim et al. (2013) demonstrated that $\mathrm{KOH}$ treatment has a great potential in creating a bioactive surface on the commercial pure $\mathrm{Ti}$ with numbers of osteoblast-like cell declining as temperature treatment increases. In this study, the apatite forming ability in DPBS solution was studied using two different types of alkaline treatment with the same concentration at temperatures of 500 and $600^{\circ} \mathrm{C}$. The effect of the alkali-heat treatment on calcium phosphate deposited on substrate was evaluated based on surface morphology, phase composition, wettability and the functional group of the apatite formation on the substrate $\mathrm{Ti}$.

\section{MATERIALS AND METHODS}

Material preparation: Titanium alloy discs $\varnothing 9.4 \times 2 \mathrm{~mm}$, Ti6Al4V ELI Grade 23 purchased from STC Company Taiwan were cleaned ultrasonically (NEYTech, $208 \mathrm{H}$, USA) in a clean glass beaker for $10 \mathrm{~min}$ with the presence of acetone, ethanol and distilled water consecutively. Then, surface modification of Ti alloy was conducted using alkali-heat treatment as reported by Kim et al. (1997) and Qu and Wei (2008). Alkali treatment was performed by soaking Ti6Al4V disc in $50 \mathrm{~mL}$ of $200 \mathrm{~g} / \mathrm{L} \mathrm{NaOH}$ (R\&M Chemicals) and $50 \mathrm{~mL}$ of $280.53 \mathrm{~g} / \mathrm{L} \mathrm{KOH} \mathrm{(R \& M}$ Chemicals) solution for $24 \mathrm{~h}$ at $60^{\circ} \mathrm{C}$ was identified as $\mathrm{S}$ and $\mathrm{P}$, respectively. This alkali treatment concentration was chosen based on the optimum alkali etching concentration of metallic implant resulting in porous network structure (Fatehii et al., 2009). Then, Ti6Al4V discs were rinsed with distilled water and dried overnight 
at room temperature. After the alkali treatment in $\mathrm{NaOH}$ and $\mathrm{KOH}$, Ti6Al4V discs were heated at 500 and $600^{\circ} \mathrm{C}$ for $1 \mathrm{~h}$ with the heating rate of $3^{\circ} \mathrm{C} / \mathrm{min}$ in a CARBOLITE furnace (CARBOLITE, ELF 11/14B, UK) and allowed to cool down in furnace after that. Samples were coded as $\mathrm{S} 500$ (heat treated at $500^{\circ} \mathrm{C}$ ), S600 (heat treated at $600^{\circ} \mathrm{C}$ ) for $\mathrm{NaOH}$ treatment while $\mathrm{P} 500$ (heat treated at $500^{\circ} \mathrm{C}$ ) and $\mathrm{P} 600$ (heat treated at $600^{\circ} \mathrm{C}$ ) for $\mathrm{KOH}$ treatment.

Apatite deposition: The apatite deposition was prepared by immersion of alkali treated Ti6Al4V in Dulbecco's Phosphate-Buffered Saline (DPBS) with additional calcium chloride and magnesium chloride (D8662, SIGMA). The ion concentration in the solution was: $\mathrm{Na}^{+}(145 \mathrm{mM}), \mathrm{K}^{+}$ (2.7 mM), $\mathrm{Mg}^{2+}(0.5 \mathrm{mM}), \mathrm{Ca}^{2+}(1.0 \mathrm{mM}), \mathrm{H}_{2} \mathrm{PO}_{4}(1.5 \mathrm{mM})$, $\mathrm{Cl}^{-}(141 \mathrm{mM})$. Each sample was immersed in $50 \mathrm{~mL}$ of DPBS solution at $37^{\circ} \mathrm{C}$ in the incubator for $72 \mathrm{~h}$ which was subsequently removed and washed thoroughly with deionized water. Samples were dried in a desiccator overnight at room temperature. Changes of $\mathrm{pH}$ DPBS solution were measured using a basic $\mathrm{pH}$ meter (Sartorius, PB-11, USA) every $12 \mathrm{~h}$. Sodium and calcium ion concentration in DPBS solution were evaluated by atomic absorption spectroscopy (Hitachi, Z2000, Japan) every 12 h. About $2 \mathrm{~mL}$ of DPBS solution were extracted out at $12 \mathrm{~h}$ intervals and then diluted using distilled water. A standard solution was carried in order to get a linear standard curve before doing sample solution analysis. Hollow cathode lamp of $\mathrm{Ca}, \mathrm{Mg}$ and $\mathrm{Na}$ was used for analysis.

Sample characterization: Morphology and trace element for all samples of Ti6Al4V were observed by using Field Emission Scanning Electron Microscope (FESEM, Carl Zeiss, SUPRA 40VP, Germany). The images of gold sputter coating samples were captured at the magnification of 1 and $10 \mathrm{k}$ at accelerated voltage of $10 \mathrm{kV}$. Meanwhile, the elemental mapping is carried out by using EDX attached with FESEM. Surface structural changes on Ti6A14V treated specimen were examined by X-ray diffraction (XRD, Rigaku, D/Max $2200 \mathrm{PC}$, Japan) using $\mathrm{CuKa}$ radiation at scan range of $(2 \theta)=20-60^{\circ}$ (scan speed: $1 \%$ min and scan step: $0.02^{\circ}$ ). The functional group presence in the apatite deposition was determined using Fourier Transform Infra-Red spectroscopy (FTIR, Perkin-Elmer, Spectrum One, USA). FTIR absorption peak was recorded in the $4000-500 \mathrm{~cm}^{-1}$ range with $4 \mathrm{~cm}^{-1}$ resolution. Wettability of the surface treated was determined by contact angle goniometry (AST Products, Inc, VCA-3000S, Massachusetts USA) using distilled water drops at room temperature. Image of water droplet was captured for measurement after $10 \mathrm{sec}$ by using static sessile drop method. The angle was calculated manually from the baseline of surface-water contact and the reading was conducted in triplicate for the average value.

\section{RESULTS AND DISCUSSION}

Morphology structure: The morphology of the alkali treated surface of Ti6Al4V is illustrated in Fig. 1. A nested porous network structure was observed on the surface of Ti6Al4V that was treated with $5 \mathrm{M} \mathrm{NaOH}$ (Fig. 1a) and $5 \mathrm{M} \mathrm{KOH}$ (Fig. $1 \mathrm{~b}$ ) at $60^{\circ} \mathrm{C}$ for $24 \mathrm{~h}$. Apparently, the porous network structure created on the surface treated with $\mathrm{NaOH}$ is finer than $\mathrm{KOH}$ treated. Reactivity of potassium earth metal was known to be slightly reactive than sodium. Thus, the chemical effect on the surface etching using $\mathrm{KOH}$ created a large macroporous network structure. A similar cellular-looking morphology on $\mathrm{NaOH}$-treated Ti6Al4v was observed by Kim et al. (2013) on commercial Ti treated with $5 \mathrm{M} \mathrm{NaOH}$. According to Cai et al. (2010), regardless of the size, porous network structure will increase the surface area of treated Ti6Al4V which then could enhance cell anchoring to adhere on the surface of the titanium implant. Then, when a porous network structure of alkali-heated Ti6Al4V was immersed in DPBS solution, the deposition of the apatite was detected on the surface of alkali-heat treated Ti6Al4V.

Figure 2 illustrates FESEM images on untreated Ti6Al4V after being immersed in DPBS solution at $37^{\circ} \mathrm{C}$ for 3 days. Figure 2 a shows the polished and shiny untreated Ti6Al4V surface that was directly immersed in DPBS solution. The globular shape apatite deposition was observed after 3 days in DPBS solution as shown in Fig. 2b. The distribution of apatite globular was unevenly formed on the surface as the smooth surface of untreated Ti6Al4V could be seen at low magnification image. While, Fig. 3 shows a FESEM images of treated Ti6Al4V after 3 days incubation in DPBS at $37^{\circ} \mathrm{C}$. Sample S, S500 and P600 surfaces were covered with a multilayer globular shape of calcium phosphate coating as shown in Fig. 3a, b and $\mathrm{f}$, respectively. Furthermore, a rosette petal-like crystal structure was captured clearly, especially for sample S treated with $5 \mathrm{M} \mathrm{NaOH}$ that has a slightly homogenous apatite globular than S500 and P600. Tas and Bhaduri (2004) reported similar findings on the rosette-like structure by a biomimetic coating of Ti6Al4V strips pre-treated with $5 \mathrm{M} \mathrm{KOH}$ and heat-treated at $600^{\circ} \mathrm{C}$. The results were also concurred by Chen et al. (2010) in which a homogenous apatite plate has successfully formed on the calcium phosphate coated surface after $15 \mathrm{~min}$ of incubation in DPBS solution in the presence of fibronectin. Meanwhile, for P, P500 and S600, the absence of globular shaped formation was observed on the surface 

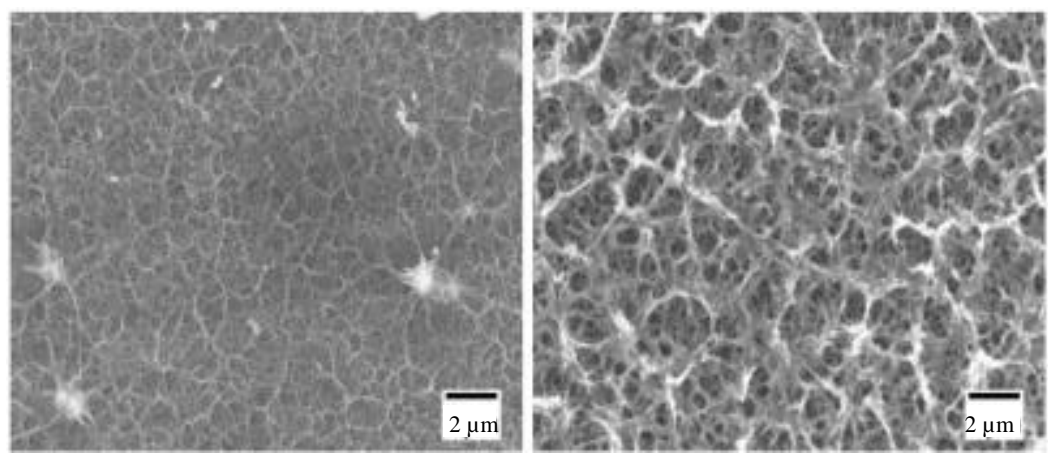

Fig. 1: FESEM image of Ti6Al4V soaked in $5 \mathrm{M} \mathrm{NaOH}$; a) and $5 \mathrm{M} \mathrm{KOH}$ and b) at $60^{\circ} \mathrm{C}$ for $24 \mathrm{~h}$
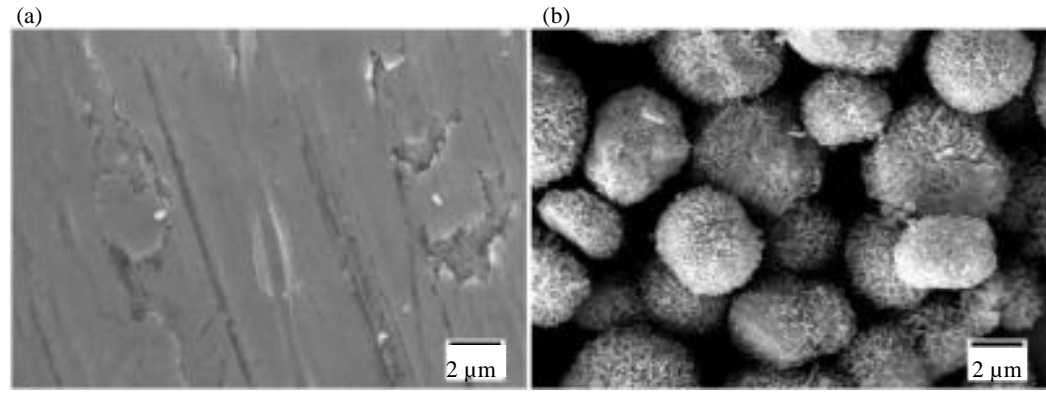

Fig. 2: a) FESEM photographs of untreated Ti6Al4V; b) A globular rosette-like structure of apatite forming on the surface of Ti6Al4V after 3 days being incubated in DPBS with $\mathrm{CaCl}_{2}$ and $\mathrm{MgCl}_{2}$ at $37^{\circ} \mathrm{C}$

(a)
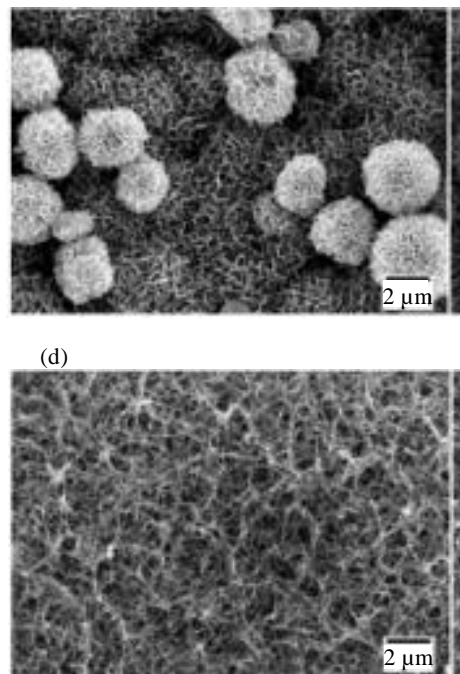

(b)

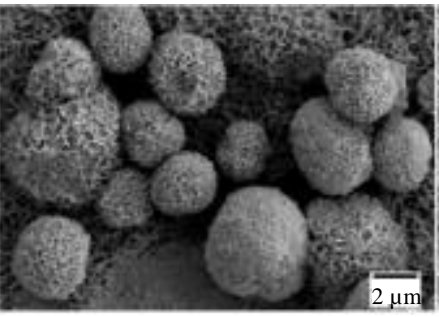

(e)

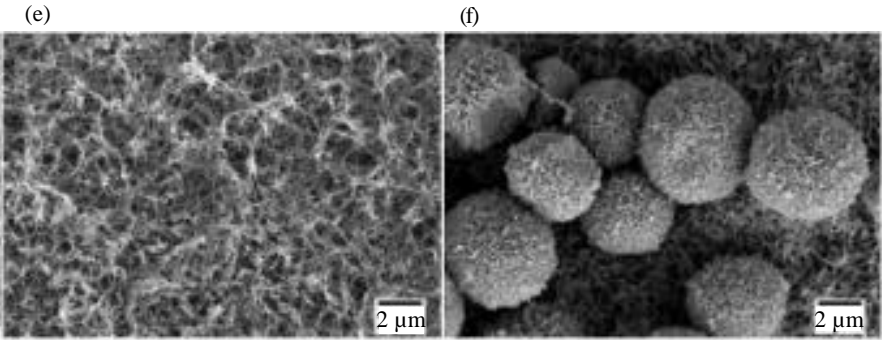

(c)

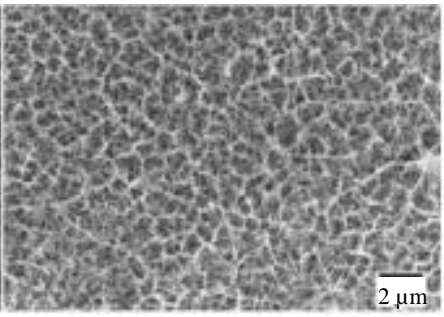

(f)

Fig. 3: a) FESEM photographs of sample S; b) S500; c) S600; d) P, P500; e) P600 and f) incubated in DPBS with $\mathrm{CaCl}_{2}$ and $\mathrm{MgCl}_{2}$ at $37^{\circ} \mathrm{C}$ for 3 days

of alkali-heat treated Ti6Al4V. On the other hand, the mesh network fibre structure on the sample $\mathrm{S} 600, \mathrm{P}$ and $\mathrm{P} 500$ as seen in Fig. 3c-e remain unchanged after immersion in DPBS solution.
Table 1 shows the weight percentage of $\mathrm{Ti}$, Calcium (Ca) and Phosphate $(\mathrm{P})$ as detected by EDX mapping analysis. Calcium to phosphate ratio of untreated Ti6Al4V, S, S500 and P600 were in the range of 1.7-2.2 


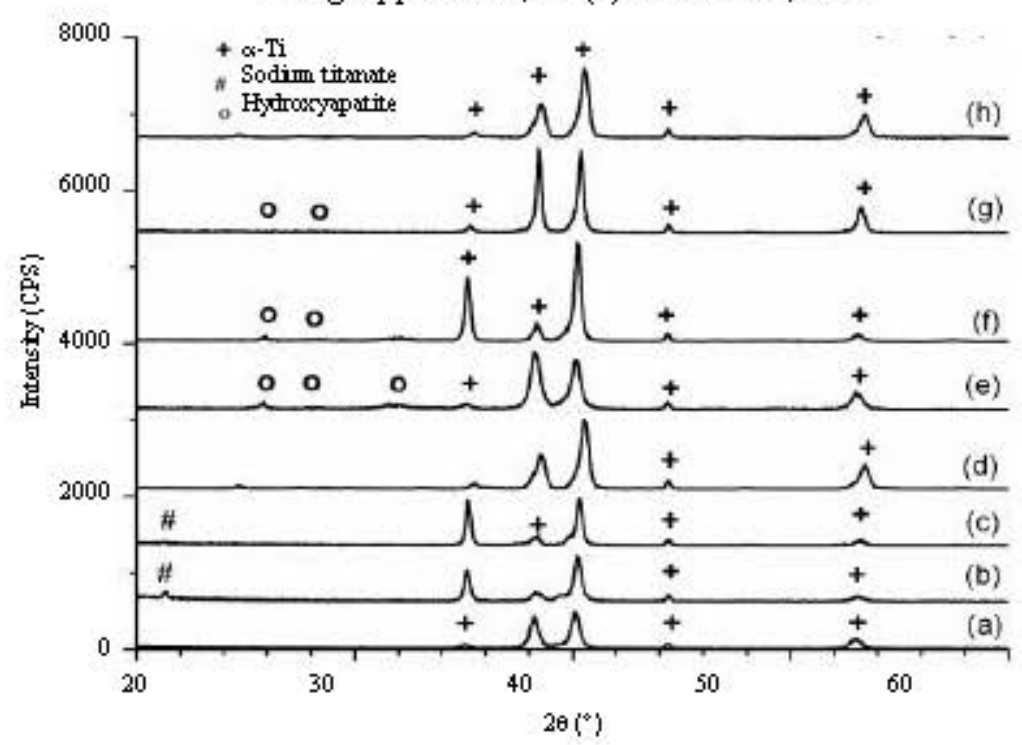

Fig. 4: a) X-ray diffraction data of untreated Ti6A14V; b) S; c) S500; d) S600; e) After soaking in DPBS of untreated Ti6A14V; f) S-DPBS; g) S500-DPBS and h) S600-DPBS samples

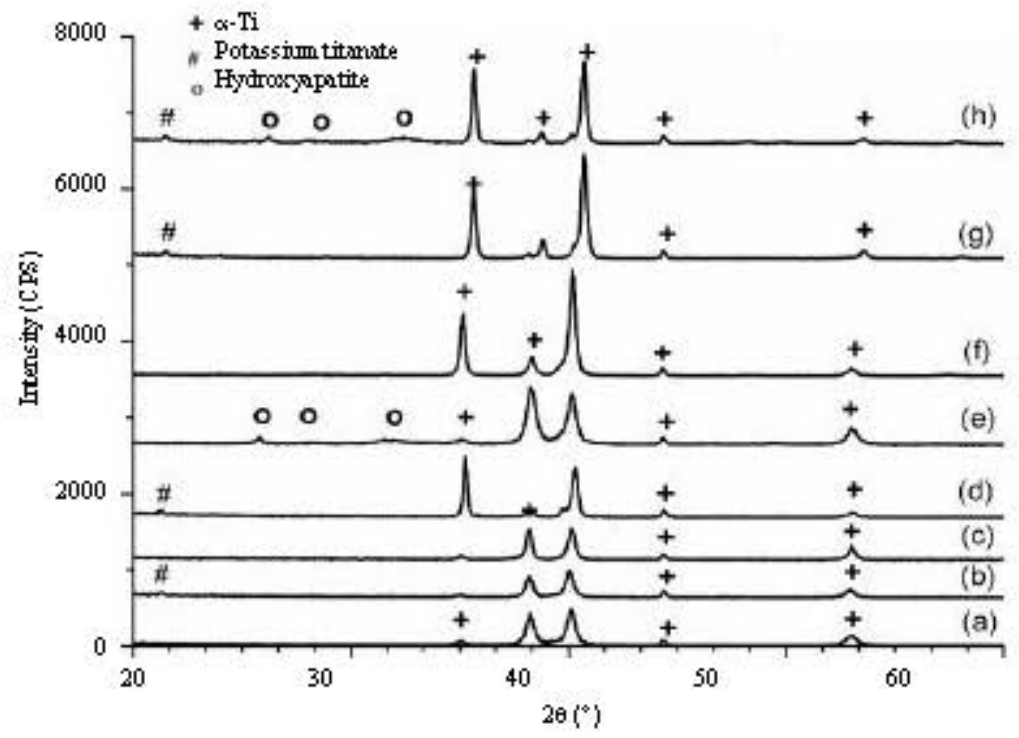

Fig. 5: a) X-ray diffraction data of untreated Ti6A14V; b) P; c) P500; d) P600; e) After soaked in DPBS of untreated Ti6A14V;f) P-DPBS; g) P500-DPBS and h) P600-DPBS samples

Table 1: Calcinm and phosphate weight percentage (wt.S\%) an costed Ti6Al4V

\begin{tabular}{lrrrr}
\hline Sample name & \multicolumn{1}{c}{$\mathrm{Ti}$} & $\mathrm{Ca}$ & $\mathrm{p}$ & $\mathrm{Ca} . \mathrm{P}$ \\
\hline Ti & 27.81 & 17.79 & 8.53 & 2.09 \\
S & 5.07 & 15.00 & 8.73 & 1.72 \\
S500 & 6.26 & 10.87 & 5.89 & 1.85 \\
S600 & 56.13 & 0.00 & 0.00 & - \\
P & 47.46 & 3.74 & 2.01 & 1.86 \\
P500 & 47.36 & 0.68 & 0.00 & - \\
P600 & 0.00 & 28.52 & 12.77 & 2.23 \\
\hline
\end{tabular}

which indicates that the apatite deposition is Carich amorphous calcium phosphate. Furthermore, the weight percentage of $\mathrm{Ti}$ has decreased as the globular shape multilayer $\mathrm{CaP}$ was completely covered on the Ti6A14V surface. Even though there is an absence of globular apatite structure on $\mathrm{S} 600$ and $P 00$ surfaces, yet the EDX analysis detected the presence of small amount of $\mathrm{Ca}$ element but lacking the phosphate element. The phase composition of apatite layer deposited on the treated surface was analysed using XRD in order to validate the presence of apatite deposition.

Phase composition determination: Figure 4 and 5 show the XRD pattem analysis on coated samples after 


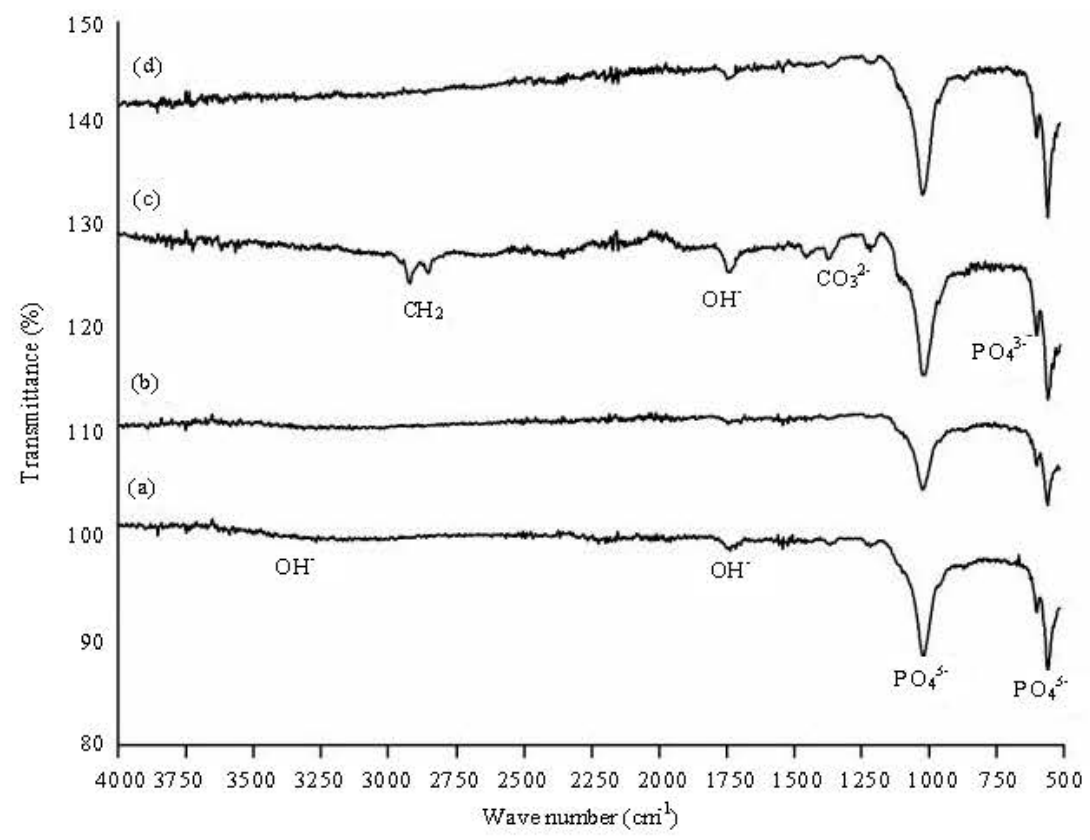

Fig. 6: a) FTIR wavelength data of DPBS-apatite deposition on untreated Ti6Al4V; b)For sample S; c) S500 and d) P600

immersion in DPBS which were being etched initially with $5 \mathrm{M} \mathrm{NaOH}$ and $5 \mathrm{M} \mathrm{KOH}$ and subsequently heat-treated at 500 and $600^{\circ} \mathrm{C}$, respectively. The untreated Ti6Al4V (Fig. 4a) pattern is recognised as a hexagonal closed-packed a-Ti (ICDD 044-1294). Treatment with 5M $\mathrm{NaOH}$ initiates a reaction with the surface of Ti6Al4V leading to the formation of sodium titanate layer as pointed out at peak $2 \theta=21.3530^{\circ}$ shown by Samples $S$ and $\mathrm{S} 500$ in Fig. $4 \mathrm{~b}$ and c, respectively. Whereas, the samples treated with $5 \mathrm{M} \mathrm{KOH}$ initially revealed a monoclinic potassium hexatitanate $\left(\mathrm{K}_{2} \mathrm{Ti}_{6} \mathrm{O}_{13}\right)$ phase peak at $(2 \theta)=21.299^{\circ}$ of sample $P$ and $(2 \theta)=21.3481^{\circ}$ of $P 600$, respectively. The reflection peaks observed are similar to the ICDD 01-074-0275 file. The oxide layer of Ti6 Al4V has been exposed to the concentrated $\mathrm{KOH}$ which led to the formation of potassium titanate layer. However, a corresponding peak of titanate layer was undetected in sample P500 (Fig. 5c) which was possibly due to a thin layer of titanate development.

After 3 days of DPBS incubation period, new peaks at low intensity were detected on XRD pattern for untreated Ti6Al4V, S, S500 and P600 samples. The presence of new peaks detected at $(2 \theta)=31.80,25.84$, $28.85^{\circ}$ with respective miller indices of $(211),(002)$ and (210) could probably be recognized as a thin deposition of apatite that corresponds to a hexagonal HA phase matching the ICDD 09-0432 file data. Meanwhile, sharp peaks detected on the diffraction pattern of all samples after $(2 \theta)=35.18-60^{\circ}$ is similar to untreated Ti6Al4V
(Fig. 4a). A diffraction peak intensity of ( $\alpha$-Ti) phase slightly decreased which indicates that the surface of Ti6A14V is concealed by the apatite deposition. A rosette petal-like structure on FESEM images of untreated Ti6A14V, S, S500 and P600 sample was a calcium phosphate apatite group as confirmed by XRD pattern. Likewise, Ceng et al. also reported that the diffraction peak near $(2 \theta)=25^{\circ}$ was recognized as bone-like apatite after incubated commercial pure titanium coated with calcium phosphate film in DPBS (magnesium free) at $37^{\circ} \mathrm{C}$ for 1 and $12 \mathrm{~h}$.

Functioning group analysis: The apatite deposited on the Ti6Al4V surface was exerted to Fourier-Transform Infrared Spectroscopy (FTIR) detector for functional group analysis. Figure 6 illustrates the bandwidth peak that is presented in the untreated Ti6 Al4V, S, S500 and P600 samples. An amorphous calcium phosphate identified in XRD is known to display the $\left(\mathrm{PO}_{4}\right)^{3}$ modes. Three peaks of $\left(\mathrm{PO}_{4}\right)^{-3}$ functional group in the IR spectrum of Fig. 6 attributed to (v3) stretching vibration modes occurring at 1021-1024 $\mathrm{cm}^{-1}$ and $(\mathrm{v})$ bending modes of $\left(\mathrm{PO}_{4}\right)^{-3}$ at 559 and $600 \mathrm{~cm}^{-1}$. There are small absorption peaks adjacent to $1024 \mathrm{~cm}^{-1}$ (around 960 and $1125 \mathrm{~cm}^{-1}$ ) which is combined to form a broad peak of $\mathrm{P}-\mathrm{O}$ stretching modes. Meanwhile, spectra of $\mathrm{S} 500$ (Fig. 6c) shows an extra absorption peak of 1369 and $1455 \mathrm{~cm}^{-1}$ indicating the incorporation of the $\mathrm{CO}_{3}^{-2}$ group into the calcium phosphate layer structure. 


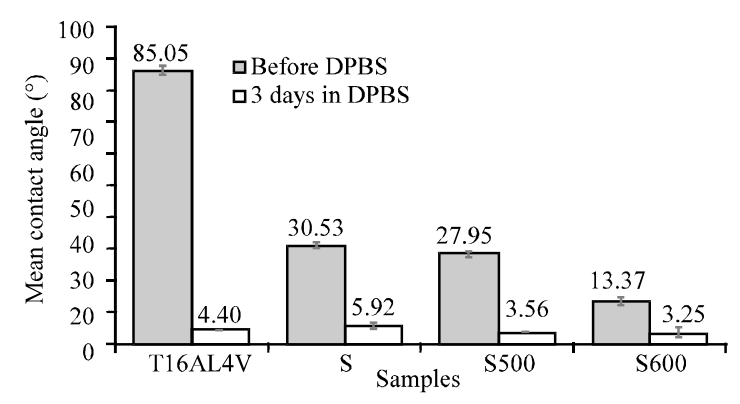

Fig. 7: Average contact angle measurements before and after DPBS immersion period of untreated, S, S500 and $\mathrm{S} 600$ samples. Vertical error bar indicates a standard deviation

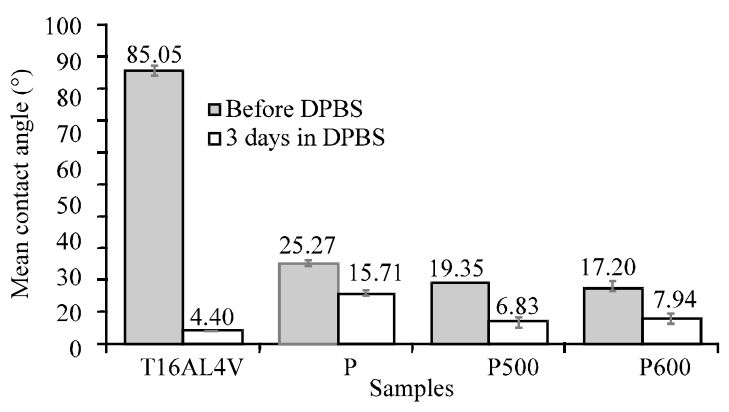

Fig. 8: Average contact angle measurements before and after DPBS immersion period of untreated, P, P500 and P600 samples. Vertical error bar indicates a standard deviation

Surface wettability: The wettability of the surfaces of untreated and alkali-heat treated samples before and after incubation in DPBS solution was compared in the contact angle measurement as shown in Fig. 7 and 8, respectively. A contact angle value indicates the affinity of the Ti6Al4V surface towards water molecules. As the contact angle value increases, the surface properties become hydrophobic. Surface modification on Ti6Al4V with $\mathrm{NaOH}$ subsequently thermally treated at 500 and 600 has changed the surface hydrophilic as values of the contact angle were drastically reduced from $85.05 \pm 1.53^{\circ}$ of untreated Ti6Al4V to the $13.37 \pm 1.23^{\circ}$. The decreasing data collected after alkali treatment was consistent with Lu et al. (2012). The contact angles of untreated Ti6Al4V before and after DPBS treatment were $85.05 \pm 1.53^{\circ}$ and $4.40 \pm 0.14^{\circ}$, respectively.

On the other hand, S, S500 and S600 samples showed a lower contact angle after 3 days being immersed into DPBS with reduced percentage of 80,87 and $76 \%$, respectively. Zhou et al. (2013) has reported that a contact angle of an etched-Ti with $5 \mathrm{M} \mathrm{NaOH}$ declined as much as $73 \%$ after being soaked in SBF assisted with microwave for $\mathrm{CaP}$ deposition. A low contact angle was influenced by the presence of hydroxyl group which attracts water molecules. Meanwhile, in the case of $\mathrm{KOH}$ etching as illustrated in Fig. 8, a similar downward trend of contact angle was observed but the value was slightly higher than $\mathrm{NaOH}$ etching (Fig. 7). Comprehensively, the wettability of Ti6Al4V surface properties decreased to $<10^{\circ}$ because calcium phosphate coating has a higher affinity towards water molecule-based components after DPBS treatment.

Ion composition study: In principal, deposition of apatite on the Ti6A14V surfaces shows the presence of a chemical reaction. Hence, ion reduction or intensification of DPBS solution was examined using Atomic Absorption Spectroscopy (AAS) and the results are presented in Fig. 9. A drastically decreased calcium ion concentration in DPBS solution was recorded as shown in Fig. 9a. This is because ion $\mathrm{Ca}$ was consumed for apatite nucleation. While $\mathrm{Mg}^{2+}$ ion seems to remain constant with $15 \%$ ion reduction. In contrast, $\mathrm{Na}^{+}$ion concentration increased and maintained after 36 h (Fig. 9b). Figure 9c demonstrated $\mathrm{pH}$ values of DPBS solution contain $\mathrm{S}$ samples that lie between 7.4 and 7.05 as a function of time. The rapid increase of $\mathrm{Na}^{+}$ion with decreased $\mathrm{pH}$ solution indicated the released of ion $\mathrm{Na}$ from the alkali treated surface $(5 \mathrm{M} \mathrm{NaOH})$ due to ion exchange with hydronium ion as reported by Kim et al. (1999).

A conventional Ti6Al4V surface covered in passive titanium oxide film prevents negative ions from invading the matrix of the alloy. This oxide layer creates a great corrosion resistance on the Ti6Al4V surface yet, it is easily destroyed and reacted with an alkaline solution (e.g., $\mathrm{NaOH}$ and $\mathrm{KOH}$ aqueous) to form an alkaline hydrogel layer. The dissolution equation of the reaction is illustrated as follows (Lee and Yoo, 2015):

$$
\begin{gathered}
\mathrm{TiO}_{2}+\mathrm{OH}^{-} \rightarrow \mathrm{HTiO}_{3}^{-} \\
\mathrm{Ti}+3 \mathrm{OH}^{-} \rightarrow \mathrm{Ti}(\mathrm{OH})_{3}^{+}+4 \mathrm{e}^{-} \\
\mathrm{Ti}(\mathrm{OH})_{3}^{+}+\mathrm{OH}^{-} \leftrightarrow \mathrm{Ti}(\mathrm{OH})_{4} \\
\mathrm{TiO}_{2} \mathrm{nH}_{2} \mathrm{O}+\mathrm{OH}^{-} \leftrightarrow \mathrm{HTiO}_{3}-\mathrm{nH}_{2} \mathrm{O}
\end{gathered}
$$

The further chemical interaction between the negatively charged species of $\mathrm{HTiO}_{3} \bullet \bullet \mathrm{nH}_{2} \mathrm{O}$ and the alkali ions $\left(\mathrm{Na}^{+} / \mathrm{K}^{+}\right)$in aqueous solution created a mechanically weak and unstable alkali titanate hydrogel layer on the treated surfaces. Heat treatment was applied to this layer in order to create a stable amorphous titanate layer as the 

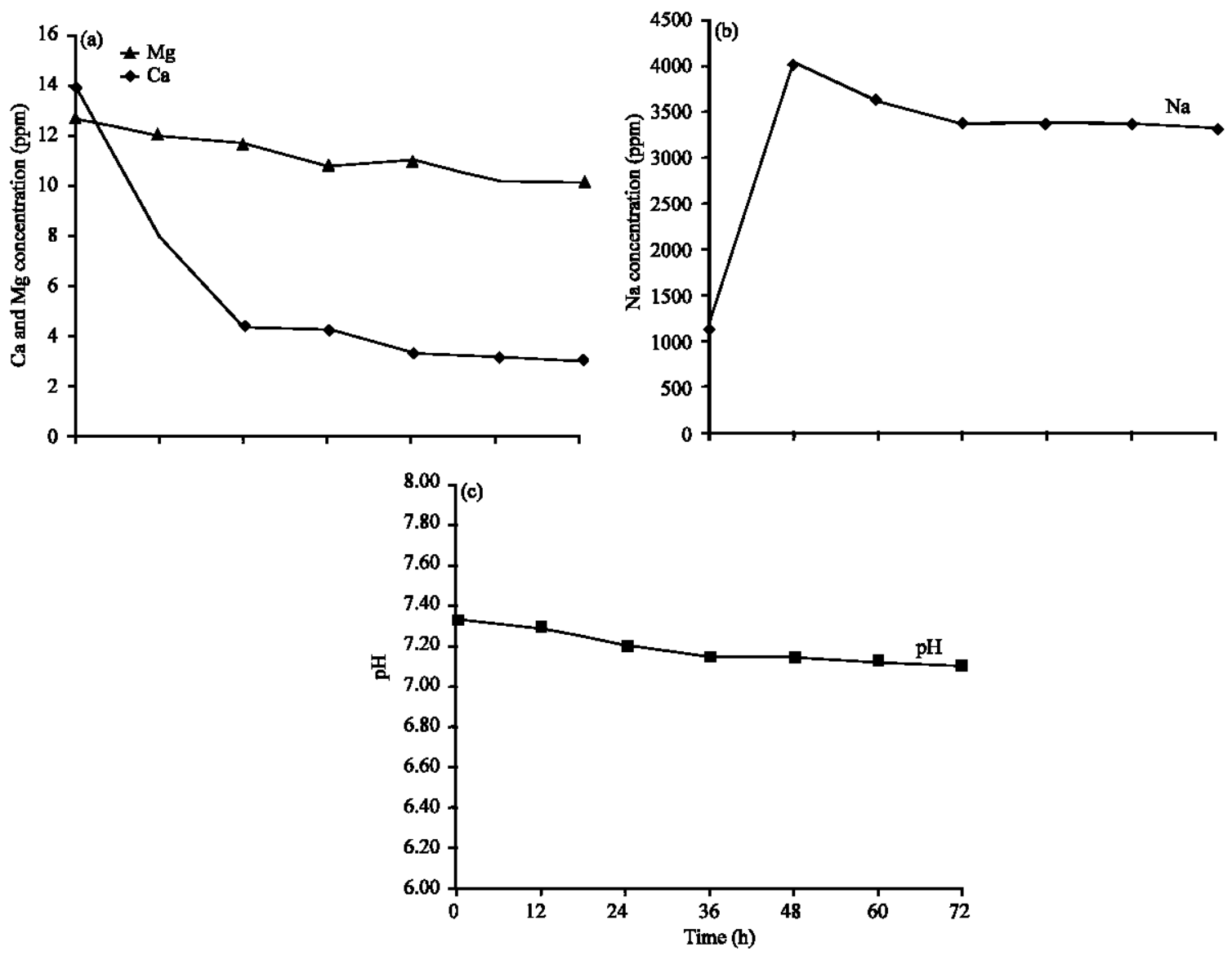

Fig. 9: a) Concentration of $\mathrm{Ca}$ and $\mathrm{Mg}$ ion; b) $\mathrm{Na}$ ion and c) $\mathrm{pH}$ monitoring values of DPBS solution at $37^{\circ} \mathrm{C}$ for $72 \mathrm{~h}$ on S sample

hydrogel layer is densified and dehydrated by heat. The presence of alkali titanate layer was confirmed by an XRD analysis. Nevertheless, subsequent heat treatment for samples S600 and P500 showed non-detected titanate peak. This might be due to the formation of a thin titanate layer. Simultaneously, sodium hydroxide treatment at high concentration produced a fine cellular-looking network structure rather than potassium hydroxide which renders to be a unique micrometre scale of nested porous morphology (Fig. 1). In basic chemistry, it is known that potassium is an alkali earth metal with reactivity slightly higher than sodium. Thus, the etching metallic metal implant in $\mathrm{KOH}$ solution creates a larger porous structure due to the reactive etching process that engraves or destroys the protective oxide layer on the metal implant surface.

During DPBS treatment, the spontaneous nanometre titanium oxide film forming on the untreated Ti surface became concentrated with Ti-OH groups as oxide surface is easily attacked by hydronium ion. The Ti-OH groups become deprotonated to form a negatively charged surface at $\mathrm{pH} 7.4$ once immersed in DPBS solution at $37^{\circ} \mathrm{C}$. Meanwhile, the alkali treated surface grander with the $\mathrm{Na}^{+} / \mathrm{K}^{+}$ions in the form of alkali titanate hydrogel layer is exchanged with hydronium ions, $\mathrm{H}_{3} \mathrm{O}^{+}$from the solution resulting in the Ti-OH layer formation (Fatehi et al., 2009). It is noticeable that the amount of $\mathrm{Na}^{+}$ion in DPBS increased after $12 \mathrm{~h}$ immersion (Fig. 9b). Simultaneously, $\mathrm{Ca}^{2+}$ ions in the solution were reduced (Fig. 9a) due to the incorporation of the $\mathrm{Ca}^{2+}$ ion with hydrated $\mathrm{Ti}-\mathrm{OH}$ layer. Accumulation of $\mathrm{Ca}^{2+}$ ion led to the positive charge titanate surface. Positively charged is preferentially attracted to negatively charged species of $\mathrm{PO}_{4}{ }^{3 \cdot}$ and $\mathrm{CO}^{2-}$ present in the DPBS to form a surface layer which is rich in an amorphous calcium phosphate (Jonasova et al., 2004). Theoretically, the release of $\mathrm{Na}^{+}$ions increased the surrounding $\mathrm{pH}$ (Kokubo and Yamaguchi, 2010). Indeed, in this case, the $\mathrm{pH}$ did not increase (Fig. 9c) at the beginning which indicates the formation of apatite nucleation or consumption of $\mathrm{H}_{3} \mathrm{O}^{+}$ions from DPBS was slowed down. Thus, the rate of apatite formation is considered to be slow. In the meantime, a small amount of 
$\mathrm{Mg}$ ion reduction was plotted in Fig. 9a as magnesium potentially adhered on the Ti surface. However, the $\mathrm{Mg}$ element was washed out after the sample was immersed in DPBS rinsed thoroughly in ultra pure water.

The apatite coverage on the untreated surface seems to be less concentrated than S, S500 and P600 samples. The smooth surface of Ti can be observed under FESEM images while the major diffraction peak of apatite was detected in XRD (Fig. 2a). Even though the apatite was deposited on the untreated surface because of the $\mathrm{Ti}-\mathrm{OH}$ group presence, the bonding of apatite on $\mathrm{Ti}$ surface is questionable due to its shiny surface of the metallic implant. Nested porous structure on the alkali treated $\mathrm{Ti}$ prepares a better apatite anchoring on the Ti surface.

In addition, releases of $\mathrm{Na}$ ion and increasing $\mathrm{pH}$ accelerates the apatite nucleation by increasing the supersaturation of the solution with respect to apatite (Fatehi et al., 2009). Increasing of the $\mathrm{pH}$ due to the apatite growth rate on the sample surface has been reported by Azhar et al. (2015).

Relatively less amount of apatite formation on sample S500 and P600 by means of heat treatment stabilise the surface structure and less sodium ion was released from the treated surface, thus, less Ti-OH layer was formed (Fatehii et al., 2009). This effect could be seen on sodium hydroxide treated samples of S, S500 and S600. As heating temperature increased, the number of apatite spherical shape formation decreased. XRD also illustrated peaks intensity of apatite detection becoming smaller and disappear as heating temperature rose. Apparently, a denser and uniform amorphous apatite was covered on the surface of the $\mathrm{NaOH}$-treated sample ( $\mathrm{S}$ ) after 3 days of immersion in DPBS. High $\mathrm{Na}$ ion released as a thick layer of Ti-OH group on the alkaline-treated Ti promoted apatite nucleation at the fastest rate.

The globular rosette petal-like structure of apatite observed are consistent with results from studies conducted by Lindahl et al. (2013) where globular rosette petal-like structure was formed after 7 days immersion of untreated Ti grade 2 in a $1 \times \mathrm{PBS}$ solution. In this present study, DPBS solution used supplementary with calcium has an affinity for the apatite formation as early as 3 days of immersion. In contrast, the apatite globular shape was unable to be observed on the surface of sample P and P500. This might be due to the incompatibility of size, porous network distribution or lack of potassium titanate hydrogel layer on the treated surface. Fatehi et al. (2009) claim that the heat treatment caused changes of surface structure which can cause lacking apatite formation. Though an amorphous apatite peaks identified by XRD analysis of P500 (Fig. 5), sample g describes the presence of small amount apatite formation, yet it is unable to be observed under FESEM analysis.
Theoretically, there are 3 main functional group bandwidth peaks that made hydroxyapatite; a hydroxyl group, a phosphate group and a carbonate group. All apatite formation on the Ti surface shows a dominant band of phosphate at the almost similar intensity. An expected hydroxyl stretch band between $3570-3500 \mathrm{~cm}^{-1}$ in the spectra has a very weak vibration mode not even a spike of intensity was detected. The presence of weak carbonate vibration mode in biomimetic apatite formation may be attributing to the disappearance of hydroxyl ions in the spectrum (Rehman and Bonfield, 1997). Yet, the carbonate ion also did not show a strong spectrum which might be due to the lack of carbonate development in the biomimetic apatite. So, the substitution of $\mathrm{CO}_{3}^{-2}$ with $\mathrm{OH}^{-}$ as characteristic absorption band is ambiguous. It is also known that the liberation bands of stoichiometric apatite are strong compared to non-stoichiometry apatite (Muller et al., 2007). Thus, biomimetic apatites deposited on the $\mathrm{Ti}$ surface probably are non-stoichiometry and non-carbonated hydroxyapatite.

Another aspect of concern which contributes towards a better bioactive implant is surface wettability. Alkali heat treatment, either sodium or potassium, both created an interconnected porous structure contributing to geometrical air trapping effects caused by wetting of hydrophilic pores (Whyman and Bormashenko, 2011). Immersion of $\mathrm{Ti}$ into DPBS solution for 3 days in the incubator has changed the wettability properties from slightly hydrophobic to hydrophilic. The formation of titanate layer in cooperation with hydroxyl group on the treated surface has the affinity to attract water molecule droplets from contact angle goniometer syringe. As detected by FTIR spectrum, the presence of a weak hydroxyl band on apatite deposited on the surface of $\mathrm{Ti}$ is superior hydrophilic. The hydroxyl group detected is from the apatite chemical composition itself and the remaining amorphous calcium titanate layer which has not been converted into amorphous calcium phosphate completely. Even though S600, P and P500 did not show apatite forming images, the amount of hydroxyl group up surged after DPBS treatment results in surface hydrophilicity. The interconnected porous structure that was not covered by apatite coating also contributed to the attraction of water molecules. Furthermore, the amount of hydroxyl group is insufficient in changing the negative charge surface which is inadequate for the attraction of the positive charge $\left(\mathrm{Ca}^{2+}\right)$ for further apatite formation. Besides, the porosity of size and morphology structure might disrupt the apatite nucleation rate. Meanwhile, Kim et al. (2013) reported a contradictory finding in which the calcium phosphate coating on the surface treated with concentrated potassium hydroxide have a slightly 
hydrophobic characteristic in the range of $55-73^{\circ}$ after 15 mins liquid-solid contact. There are no concrete studies describing the degree of hydrophilicity of biomimetic calcium phosphate in detail. At a glance, Zhou et al. (2013) reported that a microwave-assisted biomimetic apatite coating produced a superior hydrophilic surface which supports the presents study.

The human body consists of body fluid which contains $90 \%$ of water that carries proteins and ions. These components are hydrophilic and are directly in contact with the metal implant. Hence, the surface of the metallic implant is important to be in hydrophilic condition for a better adsorption of proteins which serve as substrate for bone cell growth. It is commonly reported that moderate hydrophilic characteristic of biomaterial surfaces (i.e., surfaces with high wettability) improved cell growth and implant-cell tissue interaction (Rosales-Leal et al., 2010). So, taking this into consideration, the alkali etching process was performed to activate the surface with hydroxyl group thus increase the coated metal implant wettability.

Generally, the biomimetic apatite coatings are performed for approximately seven to 14 days in SBF solution (Ting et al., 2015). There are several pre-treatment methods of manipulating the concentration and constituent of SBF solution in order to reduce the deposition time of calcium phosphate. SBF is a metastable solution especially in high concentration and it is not easy to handle its consistency and stability. Thus, in this present study, DPBS solution was used as an option for creating an environment that mimics human blood plasma to create a favourable calcium phosphate deposition. The biomimetic coating obtained for DPBS immersion represented structural features and ion composition that closely to human bone properties. In addition, surface modification in creating an active surface of Ti6Al4V was taken into consideration for further calcium phosphate deposition.

\section{CONCLUSION}

The deposition of $\mathrm{CaP}$ was detected on the alkali treated surface of Ti6Al4V after soaking in the DPBS solution for 3 days. The results showed a numerous apatite deposition after alkali treatment with $5 \mathrm{M} \mathrm{NaOH}$ (S Sample) as well as on untreated Ti6A14V, S500 and P600 samples. The surface wettability after alkali treatment and alkali-heat treatment decreased due to the presence of the interconnected porous structure. Apparently, lower contact angle after surface modification does not show a great influence on apatite deposition. DPBS solution has demonstrated apatite deposition on untreated $\mathrm{Ti}$ and treated Ti substrate within $24 \mathrm{~h}$ based on Ca ion reduction in the solution. In addition, $\mathrm{Mg}^{+}$ion concentration hastens apatite forming within $24 \mathrm{~h}$. The results of this study confirmed that the simple $\mathrm{NaOH}$-heat treatment on Ti substrate could change the topography of the metallic surface to bioactive surfaces which enhance bioactivity in DPBS solution. Coating HA via. biomimetic techniques could be fast and easy handling with the appropriate approach.

\section{ACKNOWLEDGEMENTS}

The present study was made possible through the Ministry of Sciences, Technology and Innovation (MOSTI), funding via. Research Management Institute (RMI) under the research grant [600-RMI/RAGS $5 / 3(71 / 2013)]$ and the continuous support from Institute of Graduate Studies of University Technology MARA is gratefully acknowledged.

\section{REFERENCES}

Ban, S. and S. Maruno, 1993. Deposition of calcium phosphate on titanium by electrochemical process in simulated body fluid. Jpn. J. Appl. Phys., 32: L1577L1580.

Cai, K., M. Lai, W. Yang, R. Hu and R. Xin et al., 2010. Surface engineering of titanium with potassium hydroxide and its effects on the growth behavior of mesenchymal stem cells. Acta Biomater., 6: 2314-2321.

Chen, C., I.S. Lee, S.M. Zhang and H.C. Yang, 2010. Biomimetic apatite formation on calcium phosphate-coated titanium in Dulbeccos phosphate-buffered saline solution containing $\mathrm{CaCl}_{2}$ with and without fibronectin. Acta Biomater., 6: 2274-2281.

Cosma, S.C., N. Balc, M. Moldovan and C.S. Miron-Borzan, 2015. Surface treatments applied on titanium implants. Ovidius Univ. Ann. Chem., 26: 41-48.

De Groot, K., R. Geesink, C.P.A.T. Klein and P. Serekian, 1987. Plasma sprayed coatings of hydroxylapatite. J. Biomed. Mater. Res., 21: 1375-1381.

Ducheyne, P., S. Radin, M. Heughebaert and J.C. Heughebaert, 1990. Calcium phosphate ceramic coatings on porous titanium: Effect of structure and composition on electrophoretic deposition, vacuum sintering and In vitro dissolution. Biomater., 11: 244-254.

Engh Jr, C.A., A.M. Young, C.A. Engh Sr and R.H. Hopper Jr, 2003. Clinical consequences of stress shielding after porous-coated total hip arthroplasty. Clin. Orthopaedics Relat. Res., 417: 157-163.

Fatehi, K., F. Moztarzadeh, M. Solati-Hashjin, M. Tahriri and M. Rezvannia et al., 2009. Biomimetic hydroxyapatite coatings deposited onto heat and alkali treated Ti6Al4V surface. Surf. Eng., 25: 583-588. 
Fatehii, K., F. Moztarzadehii and M.S. Hashtjiniii, 2009. Effect of Alkali and heat treatment on Biomimetic HA Coating on Ti6Al4V. AUT. J. Model. Simul., 41: 59-63.

Forsgren, J., F. Svahn, T. Jarmar and H. Engqvist, 2007. Formation and adhesion of biomimetic hydroxyapatite deposited on titanium substrates. Acta Biomater., 3: 980-984.

Geetha, M., A.K. Singh, R. Asokamani and A.K. Gogia, 2009. Ti based biomaterials, the ultimate choice for orthopaedic implants-a review. Prog. Mater. Sci., 54: 397-425.

Huang, H., P.H. Lan, Y.Q. Zhang, X.K. Li and $\mathrm{X}$. Zhang et al., 2015. Surface characterization and In vivo performance of plasma-sprayed hydroxyapatite-coated porous Ti6Al4V implants generated by electron beam melting. Surf. Coat. Technol., 283: 80-88.

Jaworski, R., L. Pawlowski, C. Pierlot, F. Roudet and S. Kozerski et al., 2009. Suspension plasma sprayed titanium oxide and hydroxyapatite coatings. Proceedings of the International Conference on Thermal Spray, May 4-7, 2009, ASM, Las Vegas, Nevada, USA., pp: 156-161.

Jonasova, L., F.A. Muller, A. Helebrant, J. Strnad and P. Greil, 2004. Biomimetic apatite formation on chemically treated titanium. Biomater., 25: 1187-1194.

Kaneko, A., S. Hirai, Y. Tamada and T. Kuzuya, 2009. Evaluation of calcium phosphate-coated silk fabric produced by Sol-Gel processing as a wound cover material. Seni Gakkaishi, 65: 97-102.

Kim, C., M.R. Kendall, M.A. Miller, C.L. Long and P.R. Larson et al., 2013. Comparison of titanium soaked in $5 \mathrm{M} \mathrm{NaOH}$ or $5 \mathrm{M} \mathrm{KOH}$ solutions. Mater. Sci. Eng. C., 33: 327-339.

Kim, H.M., F. Miyaji, T. Kokubo, S. Nishiguchi and T. Nakamura, 1999. Graded surface structure of bioactive titanium prepared by chemical treatment. J. Biomed. Mater. J. Biomed. Mater. Res., 45: 100-107.

Kim, H.M., F., Miyaji, T. Kokubo and T. Nakamura, 1997. Bonding strength of bonelike apatite layer to Ti metal substrate. J. Biomed. Mater. Res., 38: 121-127.

Klein, C.P., P.V. Patka, H.B.M. Van der Lubbe, J.G.C. Wolke and K. De Groot, 1991. Plasma sprayed coatings of tetracalcium phosphate, hydroxyl apatite and $\alpha$-Ti TCP on titanium alloy: An interface study. J. Biomed. Mater. Res., 25: 53-65.

Kokubo, T. and S. Yamaguchi, 2010. Novel bioactive titanate layers formed on $\mathrm{Ti}$ metal and its alloys by chemical treatments. Mater., 3: 48-63.

Kokubo, T., F. Miyaji, H.M. Kim and T. Nakamura, 1996. Spontaneous formation of bonelike apatite layer on chemically treated titanium metals. J. Am. Ceram. Soc., 79: 1127-1129.
Lee, K. and D. Yoo, 2015. Large-area sodium titanate nanorods formed on titanium surface via $\mathrm{NaOH}$ alkali treatment. Arch. Metall. Mater., 60: 1371-1374.

Lindahl, C., H. Engqvist and W. Xia, 2013. Influence of surface treatments on the bioactivity of Ti. ISRN. Biomater., 2013: 1-14.

Lindahl, C., W. Xia, H. Engqvist, A. Snis and J. Lausmaa et al., 2015. Biomimetic calcium phosphate coating of additively manufactured porous CoCr implants. Appl. Surf. Sci., 353: 40-47.

Lu, C.F., H.M. Huang, C.H. Chu, W.L. Li and T.F. Hong, 2012. The effects of heat treatment atmosphere on the bone-like apatite inducement on the alkali treated Ti-6Al-4 V surfaces. Procedia Eng., 36: 179-185.

Montenero, A., G. Gnappi, F. Ferrari, M. Cesari and E. Salvioli et al., 2000. Sol-gel derived hydroxyapatite coatings on titanium substrate. J. Mater. Sci., 35: 2791-2797.

Muller, L., E. Conforto, D. Caillard and F.A. Muller, 2007. Biomimetic apatite coatings-Carbonate substitution and preferred growth orientation. Biomol. Eng., 24: 462-466.

Pasinli, A., M. Yuksel, E. Celik, S. Sener and A.C. Tas, 2010. A new approach in biomimetic synthesis of calcium phosphate coatings using lactic acid-Na lactate buffered body fluid solution. Acta Biomater., 6: 2282-2288.

Qu, H. and M. Wei, 2008. The effect of temperature and initial $\mathrm{pH}$ on biomimetic apatite coating. J. Biomed. Mater. Res. Part B: Appl. Biomater., 87: 204-21 2.

Rehman, I. and W. Bonfield, 1997. Characterization of hydroxyapatite and carbonated apatite by photo acoustic FTIR spectroscopy. J. Mater. Sci. Mater. Med., 8: 1-4.

Rosales-Leal, J.I., M.A. Rodriguez-Valverde, G. Mazzaglia, P.J. Ramon-Torregrosa and L. Diaz-Rodriguez et al., 2010. Effect of roughness, wettability and morphology of engineered titanium surfaces on osteoblast-like cell adhesion. Colloids Surf. A. Physicochem. Eng. Aspects, 365: 222-229.

Tas, A.C. and S.B. Bhaduri, 2004. Rapid coating of Ti6Al4V at room temperature with a calcium phosphate solution similar to $10 \times$ simulated body fluid. J. Mater. Res., 19: 2742-2749.

Ting, N.M., O.P. Yee, T.S. Pushparajan, D. Swaminathan and M.G Kutty, 2015. Biomimetic coating of modified titanium surfaces with hydroxyapatite using simulated body fluid. Adv. Mater. Sci. Eng., 2015: 1-9.

Whyman, G. and E. Bormashenko, 2011. How to make the Cassie wetting state stable?. Langmuir, 27: 8171-8176.

Zhou, H., M. Nabiyouni and S.B. Bhaduri, 2013. Microwave assisted apatite coating deposition on Ti6Al4V implants. Mater. Sci. Eng. C., 33: 4435-4443. 